\title{
P110 $\beta$ in the ventromedial hypothalamus regulates glucose and energy metabolism
}

\author{
Teppei Fujikawa 1,2,3, Yun-Hee Choi ${ }^{1,2,4}$, Dong Joo Yang ${ }^{4}$, Dong Min Shin ${ }^{4}$, Jose Donato Jr.(1) ${ }^{1,5}$, Daisuke Kohno ${ }^{1,2,6}$, \\ Charlotte E. Lee ${ }^{1,2}$, Carol F. Elias ${ }^{1,7}$, Syann Lee ${ }^{1,2}$ and Ki Woo Kim (1) ${ }^{1,2,4}$
}

\begin{abstract}
Phosphoinositide 3-kinase (PI3K) signaling in hypothalamic neurons integrates peripheral metabolic cues, including leptin and insulin, to coordinate systemic glucose and energy homeostasis. PI3K is composed of different subunits, each of which has several unique isoforms. However, the role of the PI3K subunits and isoforms in the ventromedial hypothalamus $(\mathrm{VMH})$, a prominent site for the regulation of glucose and energy homeostasis, is unclear. Here we investigated the role of subunit $\mathrm{p110} \beta$ in steroidogenic factor-1 (SF-1) neurons of the VMH in the regulation of metabolism. Our data demonstrate that the deletion of $\mathrm{p} 110 \beta$ in SF-1 neurons disrupts glucose metabolism, rendering the mice insulin resistant. In addition, the deletion of p110 in SF-1 neurons leads to the whitening of brown adipose tissues and increased susceptibility to diet-induced obesity due to blunted energy expenditure. These results highlight a critical role for $\mathrm{p} 110 \mathrm{\beta}$ in the regulation of glucose and energy homeostasis via $\mathrm{VMH}$ neurons.
\end{abstract}

\section{Introduction}

Obesity and obesity-related metabolic diseases are major public health burdens ${ }^{1}$. The central nervous system (CNS) governs whole-body metabolism by sensing and responding to fluctuating levels of circulating cues, such as nutrients and hormones. Unraveling the neuronal mechanisms by which the CNS regulates metabolism is a fundamental step in the treatment of metabolic disease and recent scientific efforts in this area have led to a new class of Food and Drug Administration-approved antiobesity drugs ${ }^{2}$.

The hypothalamus is an important region for the regulation of metabolism ${ }^{3}$. In particular, the ventral medial nucleus of the hypothalamus (VMH) has been known since the early 1940 s, to play a critical role in the regulation of glucose and energy balance ${ }^{4,5}$. However, the molecular blueprint underlying the VMH regulation of

Correspondence: Ki Woo Kim (KIWOO-KIM@yuhs.ac)

${ }^{1}$ Division of Hypothalamic Research, Department of Internal Medicine, UT

Southwestern Medical Center, Dallas, TX 75390, USA

2Department of Pharmacology, UT Southwestern Medical Center, Dallas, TX

75390, USA

Full list of author information is available at the end of the article.

These authors contributed equally: Teppei Fujikawa, Yun-Hee Choi glucose and energy homeostasis remains unclear. Phosphoinositide 3-kinase (PI3K) is critical for the integration of metabolic hormone cues. It is composed of the regulatory subunit p 85 and the catalytic subunit p110, and each subunit comprised several variant forms. Previously, we demonstrated that mice lacking $\mathrm{p} 110 \alpha$ in the $\mathrm{VMH}$ are more prone to high-fat diet (HFD)-induced obesity and obesity-related metabolic disturbances ${ }^{6}$. Recent studies have shown distinct metabolic roles for each subunit/ variant in proopiomelanocortin (POMC) and agoutirelated peptide (AgRP) neurons of the arcuate nucleus (ARC) of the hypothalamus ${ }^{7-9}$. These studies indicate that, at least in ARC neurons, $\mathrm{p} 110 \beta$ plays a greater role in the regulation of metabolism than does $\mathrm{p} 110 \alpha$. Although electrophysiological approaches suggest that p110 $\beta$ is required for leptin and insulin action in the $\mathrm{VMH}^{10}$, the specific metabolic roles of each of the PI3K subunits in VMH neurons are not well understood. Here we investigated the role of $p 110 \beta$ in the VMH in the regulation of glucose and energy metabolism.

\section{(c) The Author(s) 2019}

(c) (i) Open Access This article is licensed under a Creative Commons Attribution 4.0 International License, which permits use, sharing, adaptation, distribution and reproduction cc) in any medium or format, as long as you give appropriate credit to the original author(s) and the source, provide a link to the Creative Commons license, and indicate if changes were made. The images or other third party material in this article are included in the article's Creative Commons license, unless indicated otherwise in a credit line to the material. If material is not included in the article's Creative Commons license and your intended use is not permitted by statutory regulation or exceeds the permitted use, you will need to obtain permission directly from the copyright holder. To view a copy of this license, visit http://creativecommons.org/licenses/by/4.0/. 


\section{Materials and methods}

Animal care and generation of tissue-specific KO mice

All experimental procedures were approved by the Institutional Animal Care and Use Committees at UT Southwestern (Dallas, TX) and Yonsei University College of Medicine. Mice were kept at room temperature $\left(22^{\circ} \mathrm{C}-24{ }^{\circ} \mathrm{C}\right.$ ) with a $12 \mathrm{~h}$ light/dark cycle (lights on at 06:00 h) and fed a normal mouse chow diet (4\% fat diet; 7001; Harlan Laboratories) or a HFD (Research Diet \#D12331; 58\% kcal from fat, 26\% from sucrose, $5.56 \mathrm{kcal} /$ g) with water provided ad libitum. To generate VMHspecific p110 $\beta$ knockout $(\mathrm{KO})\left(\mathrm{p} 110 \beta \mathrm{KO}^{\text {sf1 }}\right.$ ) mice, males that were homozygous for the floxed (F) $p 110 \beta$ allele ${ }^{11}$ and heterozygous for the $S f-1$-Cre transgene ${ }^{12}$ were crossed with female mice homozygous for the floxed $p 110 \beta$ allele. Littermate mice homozygous for the floxed $p 110 \beta$ allele $\left(p 110 \beta^{F / F}\right)$ served as controls (Ctr). All experimental mice were on a mixed C57BL/6;129S6/SvEv background.

\section{Protein and mRNA analyses}

All samples were collected between 1300 and $1500 \mathrm{~h}$ for quantitative PCR (Q-PCR) analysis. Total RNA was isolated using Trizol reagent (Invitrogen, Carlsbad, CA) and reverse transcribed with a SuperScript First-Strand Synthesis System (Invitrogen) for reverse transcriptase PCR (RT-PCR). Real-time PCR (Q-PCR) was performed using an ABI 7900 HT Sequence Detection System (Applied Biosystems, Foster City, CA). The Q-PCR primers used for the TaqMan method (Applied Biosystems) are as follows: 18S (ABI, Hs99999901), pik3ca (ABI, Mm00435673_m1), pik3cb (ABI, Mm00659576_m), pik3r1 (ABI, Mm00808818_s1), pik3c2a (ABI, Mm00478162_m1), $\beta$-adrenergic receptor 3 ( $\beta 3$-AR) (ABI, Mm02601819_g1), Cidea (ABI, Mm00432554_m1), PGC1 $\alpha$ (ABI, Mm01208835_m1), PPAR $\gamma$ (ABI, Mm01184322_m1), PRDM16 (ABI, Mm01266507_g1), uncoupling protein 1 (UCP1) (ABI, Mm01244861), and UCP3 (ABI, Mm01163394_m1).

For protein analysis, tissues from control and p110 $\beta$ $\mathrm{KO}^{\mathrm{sf} 1}$ mice were homogenized in lysis buffer $[20 \mathrm{mM}$ Tris, $5 \mathrm{mM}$ EDTA, and NP40 1\% (v/v)] containing protease inhibitors (P2714 Sigma, St. Louis, MO, resolved by SDSpolyacrylamide gel electrophoresis and finally transferred to a nitrocellulose membrane. After blocking the membrane with $5 \%$ non-fat milk, proteins were detected using the following commercially available antisera: UCP1 (Abcam, Cambridge, MA, 1:5000), GAPDH (Santa Cruz Biotech, Santa Cruz, CA, 1:5000), phosphorylation of AKT (pAKT) (Cell Signaling Technology, 1:2000), and pFoxO1 (Cell Signaling Technology, 1:1000).

\section{In situ hybridization}

RNA in situ hybridization was performed on every fourth serial section from the brains of control and $\mathrm{p} 110 \beta$
$\mathrm{KO}^{\text {sf1 }}$ mice ${ }^{13-17}$ ( $n=5$ for each genotype). Before hybridization, brain sections were mounted onto SuperFrost Plus slides (Fisher Scientific) and stored at $-20{ }^{\circ} \mathrm{C}$. Before hybridization, sections were fixed in $4 \%$ formaldehyde for $20 \mathrm{~min}$, dehydrated in ascending concentrations of ethanol, cleared in xylene for $15 \mathrm{~min}$, rehydrated in descending concentrations of ethanol, and placed in prewarmed $0.01 \mathrm{M}$ sodium citrate buffer $\mathrm{pH}$ 6.0. Sections were pretreated for $10 \mathrm{~min}$ in a microwave, dehydrated in ethanol, and air-dried. The $\mathrm{p} 110 \beta$ riboprobe was generated by in vitro transcription with ${ }^{35} \mathrm{~S}$-UTP. The ${ }^{35} \mathrm{~S}$-labeled probe was diluted $\left(10^{6} \mathrm{dpm} / \mathrm{mL}\right)$ in hybridization solution containing 50\% formamide, $10 \%$ dextran sulfate, and $1 \times$ Denhardt's solution (Sigma). The hybridization solution $(120 \mu \mathrm{l})$ was applied to each slide and incubated overnight at $56^{\circ} \mathrm{C}$. Sections were then treated with $0.002 \%$ RNAase A solution and submitted to stringency washes in decreasing concentrations of sodium chloride/sodium citrate buffer. Sections were dehydrated and enclosed in X-ray film cassettes with BMR-2 film (Kodak) for $72 \mathrm{~h}$. Slides were dipped into an NTB2 autoradiographic emulsion (Kodak), dried, and stored at $4{ }^{\circ} \mathrm{C}$ for 25 days. Slides were developed with a D-19 developer (Kodak). The $\mathrm{p} 110 \beta$ probe was produced from PCR fragments amplified with ExTaq DNA polymerase (Takara) from cDNA generated with SuperScript II Reverse Transcriptase (Invitrogen) for RT-PCR from total mouse hypothalamic RNA. The $\mathrm{p} 110 \beta$ probe comprises positions 502-762 of the NCBI reference sequence NM_029094.3 and spans exon 4 of the $P i k 3 c b$ gene. This region is flanked by LoxP sites and, therefore, this probe can be used to identify the Cre-mediated deletion of the $P i k 3 c b$ gene. All images were captured with a Nikon E1000 automated microscope installed with a Nikon digital camera (DXM 1200F; Nikon, Melville, NY).

\section{Metabolic cage studies}

A combined indirect calorimetry system (CaloSys Calorimetry System, TSE Systems, Inc., Bad Homburg, Germany) was used for all metabolic studies. Experimental animals were acclimated for 5 days in a home cage with food and water. The room temperature for all metabolic studies was maintained at $22^{\circ} \mathrm{C}$ with a $12 \mathrm{~h}$ light/dark cycle. Heat generation, $\mathrm{O}_{2}$ consumption, and $\mathrm{CO}_{2}$ production were measured after acclimation, and the relationship between metabolic rate and body mass was normalized to metabolic body size (body weight 0.75 ) unless otherwise noted. During this time, ambulatory and rearing activities were also monitored with infrared beams.

To assess diet-induced thermogenesis, chow-fed mice with matched body weights were acclimatized in the TSE metabolic chambers as described above, followed by continuous monitoring of the metabolic rate. Chow was 
provided from day 1 to day 4 and replaced with a HFD at 17:00 $\mathrm{h}$ of day 4. Metabolic parameters were measured for 3 additional days. The $\Delta \mathrm{VO}_{2}$ was calculated by the $\mathrm{VO}_{2}$ difference before and after the HFD.

\section{Hormone measurement}

Corticosterone levels were measured as previously described $^{6}$. Briefly, psychosocial stress was given to male mice by housing for $30 \mathrm{~min}$ in groups of four animals after 3 days of isolation. Trunk blood for corticosterone measurements was taken by decapitation at the indicated times (Supplementary Table 1). For follicle-stimulating hormone (FSH), luteinizing hormone ( $\mathrm{LH})$, testosterone, epinephrine, and norepinephrine measurements, serum and/or plasma were obtained between 14:00 and 15:30 h. The blood samples for corticosterone, FSH, LH, testosterone, epinephrine, and norepinephrine levels were sent for analysis to either the Ligand Assay \& Analysis Core at the University of Virginia or the Hormone Assay \& Analytical Services Core, Vanderbilt Diabetes Research and Training Center.

VMH dissection for western blotting and Q-PCR analyses

To assess leptin-mediated AKT and forkhead boxcontaining protein of the O subfamily-1 (FoxO1) phosphorylation, body weight-matched 9- to 13-week-old male mice were fasted for $18 \mathrm{~h}$ and given murine leptin $(5 \mathrm{mg} /$ kg body weight, Sigma, St. Louis, MO) or pyrogen-free saline (Sigma, St. Louis, MO). After $40 \mathrm{~min}$, the animals were transcardially perfused with $10 \%$ formalin. A coronal slice between bregma $-1.22 \mathrm{~mm}$ and $-2.06 \mathrm{~mm}$ was made, and then the $\mathrm{VMH}$ was microdissected with a scalpel under a microscope. All samples were immediately frozen on dry ice. Protein lysate was prepared from the $\mathrm{VMH}$ sample and used for western blotting analysis as described above.

To measure mRNA levels in the VMH of control and p110 $\beta \mathrm{KO}^{\text {sf1 }}$ male mice, mice were decapitated after deep anesthesia. The VMH was microdissected with a scalpel under a microscope as described above. All samples were immediately frozen on dry ice. Total mRNA was extracted and used for Q-PCR analyses.

\section{Histology}

All tissues were fixed in $10 \%$ neutral buffered formalin and either transferred to $1 \times$ phosphate-buffered saline followed by paraffin embedding or cryoembedded after sucrose infiltration for hematoxylin and eosin $(\mathrm{H} \& \mathrm{E})$, Nissl, pSTAT3, or Oil Red O staining.

\section{Body weight and composition}

The body weight of control and $\mathrm{p} 110 \beta \mathrm{KO}^{\mathrm{sf1}}$ mice fed a normal chow diet (NCD) was monitored weekly from weaning ( 4 weeks old) to 21 weeks. The body composition of control and $\mathrm{p} 110 \beta \mathrm{KO}^{\text {sf1 }}$ mice was determined using a Bruker Minispec mq10 nuclear magnetic resonance analyzer (The Woodlands, TX).

\section{GTT and ITT}

The glucose tolerance test (GTT) was performed as previously described ${ }^{18}$. Male $\mathrm{p} 110 \beta \mathrm{KO}^{\text {sf1 }}$ mice and control littermates between the ages of 20-23 weeks were fasted for $18 \mathrm{~h}$ with water provided ad libitum. After fasted glucose levels were measured, glucose was administered via intraperitoneal (i.p.) injection $(1.5 \mathrm{~g} / \mathrm{kg}$ body weight). Blood glucose levels were measured from blood sampled from tail nicks at 20, 40, 60, 90, and 120 min after injection. Blood glucose levels were determined by the glucose oxidase method using a commercial glucometer (Ascensia Contour; Bayer HealthCare, Mishawaka, IN). For the insulin tolerance test (ITT), male mice between the ages of 20-23 weeks were fasted for $2 \mathrm{~h}$ with water provided ad libitum. After measurements of basal glucose levels, insulin $(0.8 \mathrm{U} / \mathrm{kg}$, Eli Lilly and Company, HI-210, Indianapolis, IN) was administered via i.p. injection. Blood glucose levels were monitored as described above.

\section{Data analysis}

The data are presented as the mean \pm SEM, as indicated in each figure legend. Statistical significance was determined by Student's $t$-test or two-way analysis of variance. GraphPad Prism, version 5.0a (GraphPad, San Diego, CA), was used for all statistical analyses and $P<0.05$ was considered a statistically significant difference.

\section{Results}

Generation of SF-1 neuron (VMH)-specific p110 $\mathrm{KO}$ mice p $110 \beta$ is ubiquitously expressed and mice lacking $\mathrm{p} 110 \beta$ in the VMH were generated by crossing floxed $p 110 \beta$ mice $^{11}$ with steroidogenic factor- $1(S f-1)$ Cre mice $(\mathrm{p} 110 \beta$ $\left.\mathrm{KO}^{\mathrm{sf1}}\right)^{12}$, which in the CNS, express Cre recombinase exclusively in the VMH. Histological analyses confirmed that the deletion of $\mathrm{p} 110 \beta$ was confined to the VMH (Fig. $1 \mathrm{a}-\mathrm{d}$ ) without disturbing VMH cytoarchitecture (Supplementary Fig. 1). Q-PCR analysis of RNA isolated from the VMH showed that $\mathrm{p} 110 \beta$ was significantly reduced, and that the expression of the remaining isoforms and subunits was unchanged (Fig. 1e). Peripherally, SF-1 is also expressed in the pituitary, adrenal glands, and gonads, which are important tissues for the regulation of metabolism. We therefore examined these tissues for morphological changes and measured the circulating levels of corticosterone (normal and stressed), testosterone, FSH, and LH. We found similar tissue morphology and hormone parameters between the two genotypes, indicating that the hypothalamic-pituitary-adrenal and hypothalamic-pituitary-gonadal axes were intact (Supplementary Fig. 2 and Supplementary Table 1). These data 

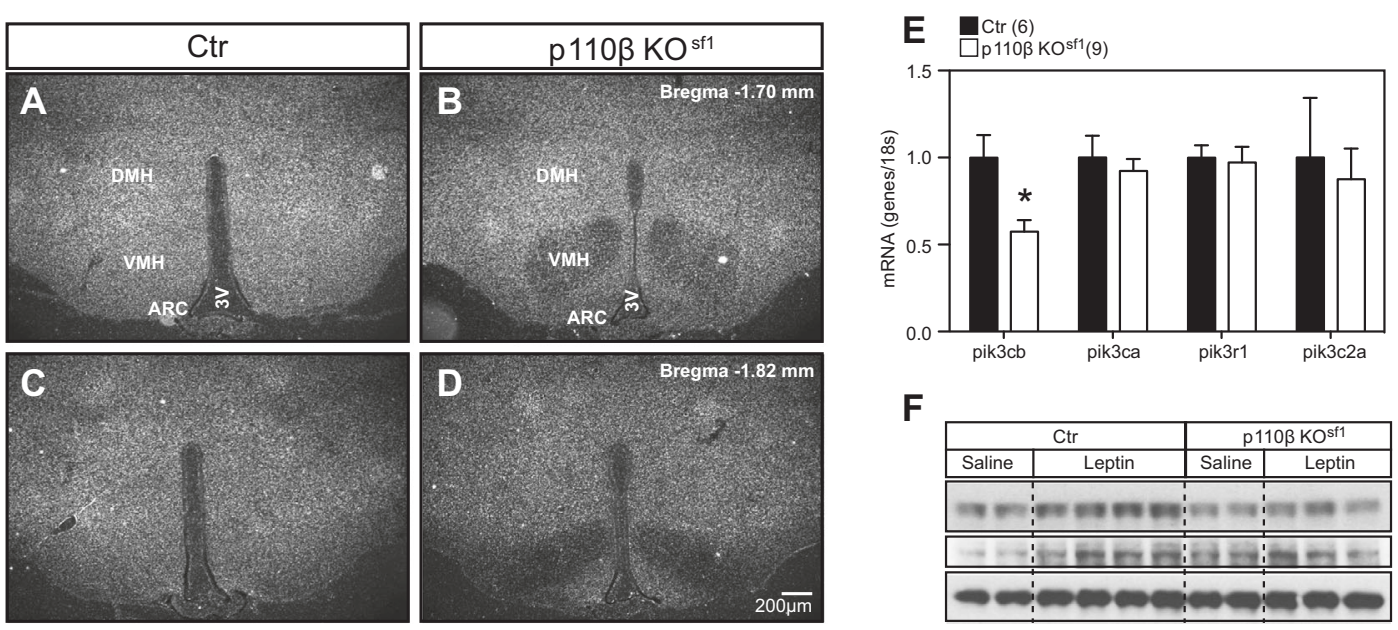

F

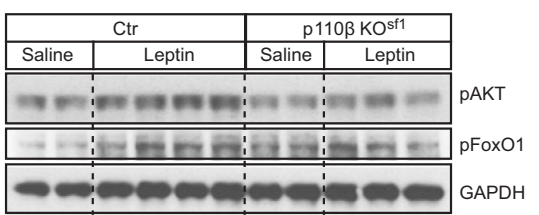

Fig. 1 Deletion of $p 110 \beta$ is restricted to SF-1 neurons of the VMH. Expression of $p 110 \beta$ detected by RNA in situ hybridization in the anterior VMH of $\mathbf{a}$ control and $\mathbf{b} \mathrm{p} 110 \beta \mathrm{KO}^{\mathrm{sf1}}$ mice, and the posterior VMH of $\mathbf{c}$ control and $\mathbf{d} \mathrm{p} 110 \beta \mathrm{KO} \mathrm{s}^{\mathrm{f} 1}$ mice. e mRNA expression of p110 $\mathrm{\beta}, \mathrm{p} 110 \mathrm{a}, \mathrm{p} 85 \mathrm{a}$, and PI3K$\mathrm{C} 2 a$ in the $\mathrm{VMH}$ of control and $\mathrm{p} 110 \beta \mathrm{KO}^{\text {sf } 1}$ mice. $\mathbf{f}$ The $\mathrm{VMH}$ was collected after i.p. administration of leptin ( $5 \mathrm{mg} / \mathrm{kg}$ body weight) and the levels of pAKT and pFoxO1 were measured in control and $\mathrm{p} 110 \beta \mathrm{KO}^{\text {sf } 1}$ mice. The number of mice in each group is indicated in the figure. ${ }^{*} P<0.05$ by Student's $t$-test. Data are shown as mean \pm SEM. Scale bar $=200 \mu \mathrm{m}$. Abbreviations: $3 \mathrm{~V}$, third ventricle; ARC, arcuate nucleus; $\mathrm{Ctr}$, control; DMH, dorsomedial nucleus of the hypothalamus

suggest that the metabolic phenotype of the $\mathrm{p} 110 \beta \mathrm{KO}^{\mathrm{sf} 1}$ mice described in this study is not secondary to disruptions in these hormones.

To determine whether the deletion of $\mathrm{p} 110 \beta$ in SF-1 neurons altered PI3K signaling in the $\mathrm{VMH}^{19}$, we measured the pAKT and FoxO1 in the VMH after intraperitoneal leptin administration $(5 \mathrm{mg} / \mathrm{kg})$. Although leptin administration activated pAKT and pFoxO1 in the $\mathrm{VMH}$ of control mice, this effect was significantly blunted in mice that lacked p110 $\beta$ (Fig. 1f). In contrast, the activation of pSTAT3 by leptin was comparable (Supplementary Fig. 3 ). These results indicate that p110 $\beta$ in SF-1 neurons of the $\mathrm{VMH}$ is necessary for the normal activation of the PI3K pathway.

\section{$\mathrm{p} 110 \beta$ isoform in the $\mathrm{VMH}$ is required for normal glucose homeostasis}

To investigate the role of $\mathrm{p} 110 \beta$ in the regulation of energy homeostasis, we first examined several metabolic parameters in mice fed a NCD. No differences were observed in body weight, body composition, leptin and insulin levels, food intake, oxygen consumption $\left(\mathrm{VO}_{2}\right)$, locomotor activity, or respiratory exchange ratio (RER) between littermate controls and $\mathrm{p} 110 \beta \mathrm{KO}^{\text {sf1 }}$ mice (Supplementary Fig. 4). Numerous studies suggest that the $\mathrm{VMH}$ is a key brain site for the regulation of glucose homeostasis through the modulation of the autonomic nervous system ${ }^{20-23}$. For instance, microinjection of leptin or orexin into the VMH increases glucose uptake and enhances insulin sensitivity, and VMH-mediated glucose uptake is blocked by inhibition of the sympathetic nervous system $(\mathrm{SNS})^{24-26}$. Although we found no significant differences in the glucose levels of mice fed a NCD, glucose levels during the refeeding period following a $24 \mathrm{~h}$ fast were significantly elevated in $\mathrm{p} 110 \beta \mathrm{KO}^{\mathrm{sf} 1}$ mice compared with control mice (Fig. 2a). Furthermore, p110 $\beta$ $\mathrm{KO}^{\text {sf1 }}$ mice exhibited blunted glucose and insulin sensitivity in response to both i.p. GTTs and ITTs (Fig. 2b-f). Notably, previous studies have shown that the deletion of p110 $\alpha$ in the VMH does not affect glucose metabolism in NCD-fed mice ${ }^{6}$. Our data suggest that glucose homeostasis by SF-1 neurons in the VMH is uniquely mediated by the $\mathrm{p} 110 \beta$ subunit.

Serum insulin levels obtained during the course of the GTT were unaltered (Fig. 2d), suggesting an impairment in insulin sensitivity rather than impaired insulin secretion from pancreatic $\beta$-cells. Therefore, we measured insulin sensitivity in peripheral tissues, including the liver, interscapular brown adipose tissue (iBAT), heart, and muscle, by monitoring the activation of pAKT after i.p. injection of insulin ${ }^{27}$. The insulin-mediated activation of pAKT was decreased in $\mathrm{p} 110 \beta \mathrm{KO}^{\mathrm{sf1}}$ mice in all tissues examined, including the iBAT, heart, and muscle, compared with control littermates (Fig. $2 g-j$ ). These results strongly suggest that the blunted insulin sensitivity in these peripheral tissues contributes to altered whole-body glucose homeostasis in $\mathrm{p} 110 \beta \mathrm{KO}^{\mathrm{sf1}}$ mice.

\section{Increased whitening of iBAT and decreased energy expenditure in $\mathrm{p} 110 \beta \mathrm{KO}^{\text {sf } 1}$ mice}

The VMH is a critical brain site mediating sympathetic tone to the $\mathrm{BBAT}^{25,28,29}$. A disruption in $\beta$-adrenergic 

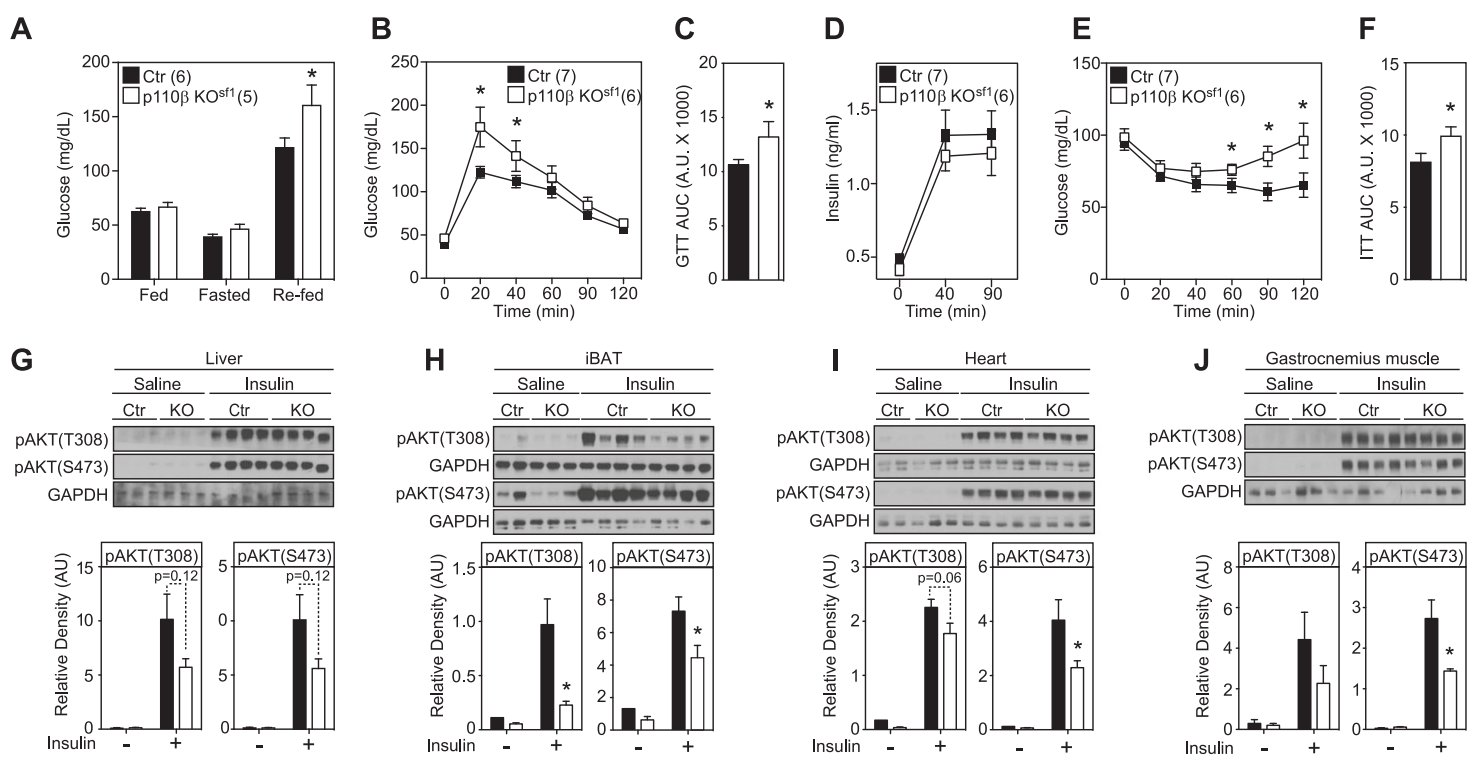

Fig. 2 Deletion of $\mathbf{p} 110 \beta$ in SF-1 neurons disrupts glucose and insulin homeostasis. a Glucose levels in fed ( $3 \mathrm{~h}$ fasted), fasted ( $24 \mathrm{~h})$, and refed $(1 \mathrm{~h})$ male mice. b GTT [significant interaction (two-way repeated ANOVA, $F_{5.62}=37.65, p<0.0001$ )]. c Area under the curve (AUC) from $\mathbf{b}$. $\mathbf{d}$ Insulin levels during the GTT. e ITT [significant interaction (two-way repeated ANOVA, $F_{1.66}=14.84, p=0.00003$ )]. $\mathbf{f}$ Area under the curve (AUC) from $\mathbf{e}$. Blunted insulin-induced pAKT activation in the $\mathbf{g}$ liver, $\mathbf{h}$ iBAT, $\mathbf{i}$ heart, and $\mathbf{j}$ gastrocnemius muscle of $\mathrm{p} 110 \beta \mathrm{KO}^{\mathrm{sf} 1}$ mice. Number of mice in each group is indicated in the legends or directly in the figures. Data are shown as the mean \pm SEM. ${ }^{*} P<0.05$ by Student's $t$-test

signaling causes iBAT lipid accumulation ${ }^{30,31}$, a process known as "whitening" ${ }^{31}$. Notably, the activation of pAKT in the iBAT after insulin administration was significantly blunted in $\mathrm{p} 110 \beta \mathrm{KO}^{\text {sfl }}$ mice (Fig. 2h). H\&E staining revealed an increase in lipid droplets in $\mathrm{p} 110 \beta \mathrm{KO}^{\text {sf1 }}$ mice (Fig. 3a-c). In addition, the RNA levels of $\beta 3-A R$ and $\mathrm{UCP} 1$, and the protein levels of UCP1 were significantly reduced in the iBAT of $\mathrm{p} 110 \beta \mathrm{KO}^{\text {sf1 }}$ mice (Fig. $3 \mathrm{~d}-\mathrm{f}$ ). Moreover, plasma norepinephrine, a neurotransmitter released by sympathetic nerve terminals, was decreased in p110 $\beta \mathrm{KO}^{\text {sf1 }}$ mice (Fig. 3g). Our study demonstrates that the deletion of p110 $\beta$ in SF-1 neurons hampers sympathetic activity and leads to the whitening of iBAT. Collectively, these data suggest that $\mathrm{p} 110 \beta$ expression in the $\mathrm{VMH}$ is a key module to maintain BAT programming.

As p110 $\beta \mathrm{KO}^{\text {sf1 }}$ mice displayed changes in sympathetic tone, we postulated that metabolic stress would alter metabolic homeostasis in $\mathrm{p} 110 \beta \mathrm{KO}^{\mathrm{sf1}}$ mice. Of note, a HFD decreases UCP1, PGC1 $\alpha$, and other genes, which are important for maintaining BAT programming ${ }^{31}$. To address this hypothesis, metabolic stress was induced by challenging mice with a HFD and assessing the metabolic response of $\mathrm{p} 110 \beta \mathrm{KO}^{\text {sf1 }}$ mice. The body weight of $\mathrm{p} 110 \beta$ $\mathrm{KO}^{\text {sf1 }}$ mice began to diverge from that of control mice after 6 weeks of HFD feeding (Fig. 4a). The increased body weight was caused by increased fat mass but not lean mass (Fig. 4b, c). Indirect calorimetry studies revealed significantly decreased oxygen consumption in $\mathrm{p} 110 \beta \mathrm{KO}^{\text {sf } 1}$ mice, without changes in food intake, movement, or the
RER during HFD feeding (Fig. 4d-h). These data imply that PI3K activity in SF-1 neurons of the VMH might be necessary for the regulation of energy expenditure, especially under high-calorie conditions. Serum analysis showed elevated levels of leptin, insulin, fasted glucose, triglyceride (TG), and free fatty acid in HFD-fed p110 $\mathrm{KO}^{\text {sf1 }}$ mice (Fig. 4i-m). In addition, HFD-fed p110 $\mathrm{KO}^{\text {sf1 }}$ mice exhibited increased liver TG (Fig. 4n) but not serum or liver cholesterol (Fig. 4o, p). These results indicate that the $\mathrm{p} 110 \beta$ subunit in the VMH might be involved in the regulation of metabolic homeostasis.

\section{Discussion}

Although the metabolic importance of PI3K has been shown in several tissues, little is known about its function in the hypothalamus ${ }^{6,9,11}$. In this study, we specifically deleted the $\mathrm{p} 110 \beta$ isoform of PI3K from SF-1 neurons of the $\mathrm{VMH}$. We found that $\mathrm{p} 110 \beta$ in the $\mathrm{VMH}$, possibly through actions on the autonomic nervous system, is required for energy homeostasis and the maintenance of normal glucose and insulin sensitivity. p110 $\alpha$ and $\mathrm{p} 110 \beta$ are class IA PI3K isoforms, and studies using global $\mathrm{KO}$ mice have suggested that each isoform has distinct metabolic functions ${ }^{32,33}$. Notably, the deletion of class I PI3K isoforms in ARC POMC or AgRP neurons revealed that $\mathrm{p} 110 \beta$ has a greater contribution than does $\mathrm{p} 110 \alpha$ to metabolic parameters, such as body weight, food intake, and leptin-mediated neuronal excitability ${ }^{9,34}$. Our studies have extended these findings to the VMH. We previously 
A

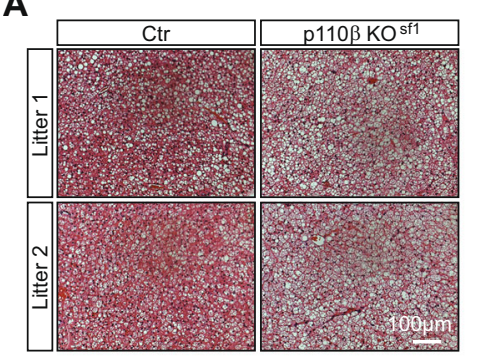

D

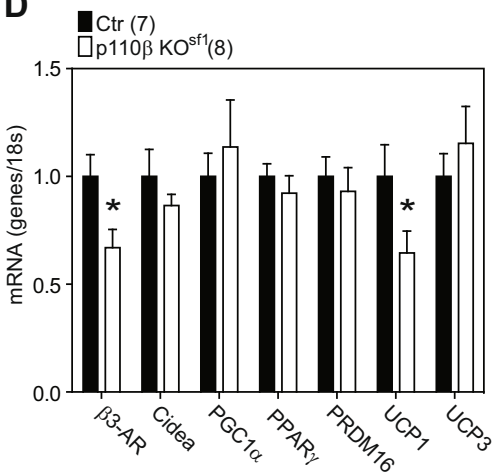

B

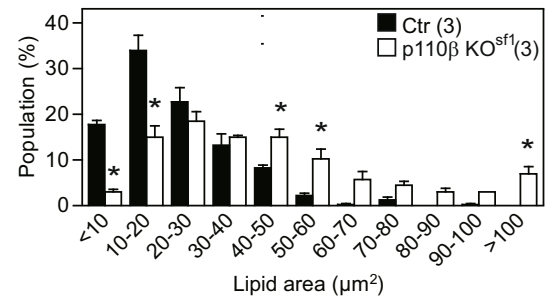

$\mathbf{E}$

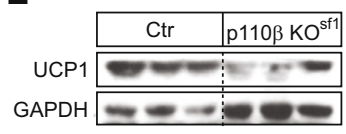

$\mathbf{F}$

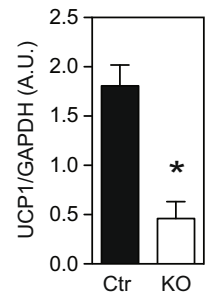

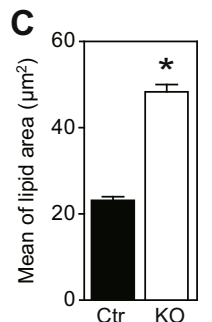

G

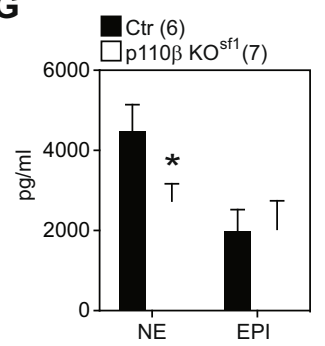

Fig. 3 Deletion of $\mathbf{p} 110 \beta$ in SF-1 neurons leads to the whitening of iBAT. a Hematoxylin and eosin staining of iBAT from control and p1 $10 \beta$ KO ${ }^{\text {f } 1}$ mice. $\mathbf{b}$ Distribution (\% of population) of lipid droplets from a [significant interaction (two-way ANOVA, $\mathrm{F}_{1.20}=18.02, p=0.0001$ )]. $\mathbf{c}$ Mean lipid area $\left(\mu \mathrm{m}^{2}\right)$ of the droplets from $\mathbf{a}$. $\mathbf{d}$ mRNA levels of genes in iBAT regulating BAT programming. e UCP1 protein levels in the iBAT of control and p110 $\mathrm{KO}^{\mathrm{sf1}}$ mice. $\mathbf{f}$ Average UCP1 protein levels in the iBAT of control and $\mathrm{p} 110 \beta \mathrm{KO}^{\mathrm{sf1}}$ mice. $\mathbf{g}$ Plasma norepinephrine and epinephrine levels in chow-fed males. Number of mice in each group is indicated in the legends or directly in the figures. Data are shown as the mean \pm SEM. ${ }^{*} P<0.05$ by Student's t-test. EPI, epinephrine; Ctr, control; NE, norepinephrine

showed that p110 $\alpha$ deletions in the VMH affect dietinduced obesity but not the basal metabolic rate ${ }^{6}$. Our current study shows that p110 $\beta$ in SF- 1 neurons of the $\mathrm{VMH}$ plays a much broader role, affecting glucose and insulin homeostasis and BAT function.

The VMH is well known to regulate many physiological processes, including energy expenditure, reproduction, defensive behavior, food intake, carbohydrate and fat metabolism, and metabolic adaptation ${ }^{6,12,18,23,29,35-57}$. In 1966, Shimazu et al. ${ }^{35}$ demonstrated that electric stimulation of the VMH remarkably increased blood glucose and suggested the important role of the $\mathrm{VMH}$ in the regulation of glucose metabolism ${ }^{56,57}$. Previous reports have indicated that microinjection of leptin into the VMH can stimulate glucose uptake into the peripheral tissues, including skeletal muscle ${ }^{25}$. We recently found that the p110 $\beta$ subunit is required for leptin-induced depolarization in SF-1 neurons of the $\mathrm{VMH}^{10}$. Collectively, these studies suggest that the deletion of $\mathrm{p} 110 \beta$ in SF-1 neurons may compromise leptin's glucoregulatory actions, leading to refractory responses to the GTT. Interestingly, we found that $\mathrm{p} 110 \beta \mathrm{KO}^{\text {sf1 }}$ mice exhibited glucose intolerance under refed conditions, with no significant body weight change, and exhibited diet-induced obesity, with significantly increased fasted glucose levels. p110 $\beta \mathrm{KO}^{\text {sf1 }}$ mice exhibited insulin insensitivity in the iBAT, heart, and gastrocnemius muscle. These results highly imply that the higher glucose level in $\mathrm{p} 110 \beta \mathrm{KO}^{\text {sf1 }}$ mice might be the result of decreased glucose uptake and insulin sensitivity mediated by decreased sympathetic tone.

A recent paper showed that SNS input is necessary for maintaining the thermogenic properties of $\mathrm{BAT}^{31}$. Disruption of the SNS signaling pathway leads to a whitening of BAT accompanied by a reduction in mitochondrial activity and the accumulation of lipid droplets ${ }^{51}$. In fact, $o b / o b^{58}$ and $\mathrm{DIO}^{31}$ mice show impaired SNS and BAT whitening. The $\mathrm{VMH}$ regulates BAT function via the $\mathrm{SNS}^{24,25,36,41}$. Lesions in the VMH have been shown to cause mitochondrial dysfunction and to reduce fatty acid oxidation $^{59-61}$, indicating that an intact VMH is important for maintaining BAT function. Lower levels of norepinephrine together with increased iBAT whitening in p110 $\beta \mathrm{KO}^{\text {sf1 }}$ mice suggest that $\mathrm{p} 110 \beta$ in the $\mathrm{VMH}$ might be a critical component for the SNS-mediated BAT pathway, while further analyses including the direct visualization of sympathetic nerve fibers are necessary.

Our study supports the notion that the VMH plays a critical role in regulating metabolic adaptations under 


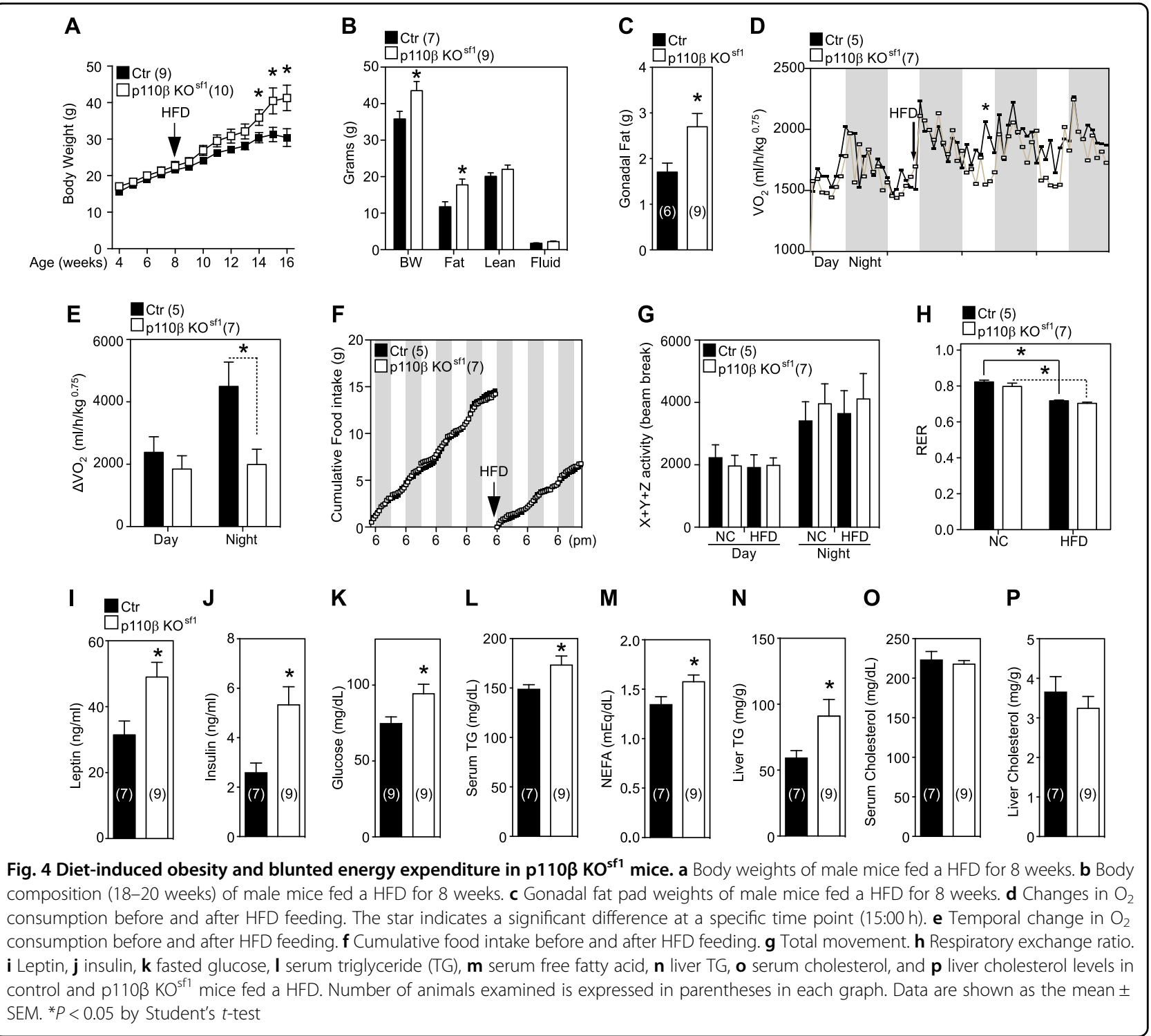

conditions requiring high-energy expenditure, such as a HFD and exercise ${ }^{6,12,48,50,53,55,62}$. The regulation of energy expenditure by the VMH is known to be mediated by the SNS; however, the precise neuronal pathway linking the SNS and the VMH has not yet been precisely determined. Genetic tracing experiments revealed that SF-1 neurons project to several brain nuclei that regulate SNS function $^{63}$; thus, future studies using emerging techniques such as channel rhodopsin-assisted neurocircuit mapping $^{64}$ may provide further insights into the functional pathways linking the SNS and the VMH. In summary, the current study suggests that pharmaceutical therapies that target PI3K in a tissue- and isoform-specific manner may prove beneficial toward ameliorating metabolic syndrome, especially diabetes.

\section{Acknowledgements}

We thank Dr. Joel K. Elmquist (UT Southwestern Medical Center) for guidance and suggestions. We also thank Laura Brule, Min Kim, Danielle Lauzon, and Linh-An Cao for technical assistance and the Metabolic Phenotyping Core at the University of Texas Southwestern Medical Center (supported by PL1 DK081182 and UL1RR024923). Funding for these studies was provided to T.F. (Juvenile Diabetes Research Foundation postdoctoral fellowship 3-2011-405 and an American Heart Association Scientist Development Grant 14SDG17950008), C.F.E. (NIH grant R01HD061539), and K.W.K. (Korea Health Industry Development Institute HI17C0745 and the National Research Foundation NRF-2016R1C1B3012748 and NRF-2016R1A5A2008630).

\section{Author details}

${ }^{1}$ Division of Hypothalamic Research, Department of Internal Medicine, UT Southwestern Medical Center, Dallas, TX 75390, USA. ${ }^{2}$ Department of Pharmacology, UT Southwestern Medical Center, Dallas, TX 75390, USA. ${ }^{3}$ Department of Cellular and Integrative Physiology, Long School of Medicine, UT Health San Antonio, San Antonio, TX, USA. ${ }^{4}$ Department of Oral Biology, BK21 PLUS, Yonsei University College of Dentistry, Seoul 03722, Korea.

${ }^{5}$ Department of Physiology and Biophysics, Institute of Biomedical Sciences, 
University of São Paulo, São Paulo, SP 05508000, Brazil. ${ }^{6}$ Metabolic Signal Research Center, Institute for Molecular and Cellular Regulation, Gunma University, Maebashi 371-8512, Japan. ${ }^{7}$ Department of Molecular and Integrative Physiology, University of Michigan, Ann Arbor, MI, USA

\section{Author contributions}

T.F., Y.H.C., S.L. and K.W.K. designed the experiments. T.F., Y.H.C., D.J.Y., D.M.S., J. D., D.K., C.E.L., C.F.E. and K.W.K. conducted and analyzed the experiments. T.F., Y. H.C., S.L. and K.W.K. wrote the manuscript. All authors discussed the results and commented on the manuscript.

\section{Conflict of interest}

The authors declare that they have no conflict of interest.

\section{Publisher's note}

Springer Nature remains neutral with regard to jurisdictional claims in published maps and institutional affiliations.

Supplementary information accompanies this paper at https://doi.org/ 10.1038/s12276-019-0249-8.

Received: 14 September 2018 Revised: 10 January 2019 Accepted: 23 January 2019.

Published online: 26 April 2019

\section{References}

1. Dobbs, R. et al. How the world could better fight obesity (The McKinsey Global Institute, 2014)

2. Gautron, L., Elmquist, J. K. \& Williams, K. W. Neural control of energy balance: translating circuits to therapies. Cell 161, 133-145 (2015).

3. Morton, G. J., Meek, T. H. \& Schwartz, M. W. Neurobiology of food intake in health and disease. Nat. Rev. Neurosci. 15, 367-378 (2014).

4. Hetherington, A. W. The relation of various hypothalamic lesions to adiposity and other phenomena in the rat. Am. J. Physiol. 133, 326-327 (1941).

5. Choi, Y. H., Fujikawa, T., Lee, J., Reuter, A. \& Kim, K. W. Revisiting the ventral medial nucleus of the hypothalamus: the roles of SF-1 neurons in energy homeostasis. Front. Neurosci. 7, 1-9 (2013).

6. $\mathrm{Xu}, \mathrm{Y}$. et al. PI3K signaling in the ventromedial hypothalamic nucleus is required for normal energy homeostasis. Cell Metab. 12, 88-95 (2010).

7. Hill, J. W. et al. Phosphatidyl inositol 3-kinase signaling in hypothalamic proopiomelanocortin neurons contributes to the regulation of glucose homeostasis. Endocrinology 150, 4874-4882 (2009).

8. Hill, J. W. et al. Direct insulin and leptin action on pro-opiomelanocortin neurons is required for normal glucose homeostasis and fertility. Cell Metab. 11, 286-297 (2010).

9. Al-Qassab, H. et al. Dominant role of the p110beta isoform of PI3K over p110alpha in energy homeostasis regulation by POMC and AgRP neurons. Cell Metab. 10, 343-354 (2009).

10. Sohn, J. W. et al. Leptin and insulin engage specific PI3K subunits in hypothalamic SF1 neurons. Mol. Metab. 5, 669-679 (2016).

11. Jia, S. et al. Essential roles of PI(3)K-p110beta in cell growth, metabolism and tumorigenesis. Nature 454, 776-779 (2008).

12. Dhillon, H. et al. Leptin directly activates SF1 neurons in the VMH, and this action by leptin is required for normal body-weight homeostasis. Neuron $\mathbf{4 9}$ 191-203 (2006).

13. Kishi, $T$. et al. Expression of melanocortin 4 receptor mRNA in the central nervous system of the rat. J. Comp. Neurol. 457, 213-235 (2003).

14. Kim, K. W. et al. Steroidogenic factor 1 regulates expression of the cannabinoid receptor 1 in the ventromedial hypothalamic nucleus. Mol. Endocrinol. 22, 1950-1961 (2008).

15. Zhao, L. et al. Central nervous system-specific knockout of steroidogenic factor 1 results in increased anxiety-like behavior. Mol. Endocrinol. 22, 1403-1415 (2008).

16. Tong, Q. et al. Synaptic glutamate release by ventromedial hypothalamic neurons is part of the neurocircuitry that prevents hypoglycemia. Cell Metab. $\mathbf{5}$ 383-393 (2007).

17. Elias, C. F. et al. Chemical characterization of leptin-activated neurons in the rat brain. J. Comp. Neurol. 423, 261-281 (2000).
18. Bingham, N. C., Anderson, K. K., Reuter, A. L., Stallings, N. R. \& Parker, K. L. Selective loss of leptin receptors in the ventromedial hypothalamic nucleus results in increased adiposity and a metabolic syndrome. Endocrinology 149, 2138-2148 (2008).

19. Williams, K. W., Scott, M. M. \& Elmquist, J. K. Modulation of the central melanocortin system by leptin, insulin, and serotonin: co-ordinated actions in a dispersed neuronal network. Eur. J. Pharm. 660, 2-12 (2011).

20. Cotero, V. E. \& Routh, V. H. Insulin blunts the response of glucose-excited neurons in the ventrolateral-ventromedial hypothalamic nucleus to decreased glucose. Am. J. Physiol. Endocrinol. Metab. 296, E1101-E1109 (2009).

21. Borg, M. A., Sherwin, R. S., Borg, W. P., Tamborlane, W. V. \& Shulman, G. I. Local ventromedial hypothalamus glucose perfusion blocks counterregulation during systemic hypoglycemia in awake rats. J. Clin. Invest. 99, 361-365 (1997).

22. Borg, W. P. et al. Ventromedial hypothalamic lesions in rats suppress counterregulatory responses to hypoglycemia. J. Clin. Invest. 93, 1677-1682 (1994).

23. Borg, W. P., Sherwin, R. S., During, M. J., Borg, M. A. \& Shulman, G. I. Local ventromedial hypothalamus glucopenia triggers counterregulatory hormone release. Diabetes 44, 180-184 (1995).

24. Haque, M. S. et al. Role of the sympathetic nervous system and insulin in enhancing glucose uptake in peripheral tissues after intrahypothalamic injection of leptin in rats. Diabetes 48, 1706-1712 (1999).

25. Minokoshi, Y., Haque, M. S. \& Shimazu, T. Microinjection of leptin into the ventromedial hypothalamus increases glucose uptake in peripheral tissues in rats. Diabetes 48, 287-291 (1999).

26. Shiuchi, T. et al. Hypothalamic orexin stimulates feeding-associated glucose utilization in skeletal muscle via sympathetic nervous system. Cell Metab. 10, 466-480 (2009).

27. $L u, M$. et al. Insulin regulates liver metabolism in vivo in the absence of hepatic Akt and Foxo1. Nat. Med. 18, 388-395 (2012).

28. Rothwell, N. J. \& Stock, M. J. A role for brown adipose tissue in diet-induced thermogenesis. Nature 281, 31-35 (1979).

29. Minokoshi, Y., Saito, M. \& Shimazu, T. Sympathetic denervation impairs responses of brown adipose tissue to VMH stimulation. Am. J. Physiol. 251 R1005-R1008 (1986)

30. Bachman, E. S. et al. betaAR signaling required for diet-induced thermogenesis and obesity resistance. Science 297, 843-845 (2002).

31. Shimizu, l. et al. Vascular rarefaction mediates whitening of brown fat in obesity. J. Clin. Invest. 124, 2099-2112 (2014).

32. Foukas, L. C. et al. Critical role for the p110alpha phosphoinositide-3-OH kinase in growth and metabolic regulation. Nature 441, 366-370 (2006).

33. Ciraolo, E. et al. Phosphoinositide 3-kinase p110beta activity: key role in metabolism and mammary gland cancer but not development. Sci. Signal. 1, ra3 (2008).

34. Hill, J. W. et al. Acute effects of leptin require PI3K signaling in hypothalamic proopiomelanocortin neurons in mice. J. Clin. Invest. 118, 1796-1805 (2008).

35. Shimazu, T., Fukuda, A. \& Ban, T. Reciprocal influences of the ventromedial and lateral hypothalamic nuclei on blood glucose level and liver glycogen content. Nature 210, 1178-1179 (1966)

36. Perkins, M. N., Rothwell, N. J., Stock, M. J. \& Stone, T. W. Activation of brown adipose tissue thermogenesis by the ventromedial hypothalamus. Nature $\mathbf{2 8 9}$, 401-402 (1981).

37. Shimazu, T. \& Ishikawa, K. Modulation by the hypothalamus of glucagon and insulin secretion in rabbits: studies with electrical and chemical stimulations. Endocrinology 108, 605-611 (1981).

38. Takahashi, A. \& Shimazu, T. Hypothalamic regulation of lipid metabolism in the rat: effect of hypothalamic stimulation on lipolysis. J. Auton. Nerv. Syst. $\mathbf{4}$, 195-205 (1981).

39. Vander Tuig, J. G., Knehans, A. W. \& Romsos, D. R. Reduced sympathetic nervous system activity in rats with ventromedial hypothalamic lesions. Life Sci. 30, 913-920 (1982).

40. Sakaguchi, T. \& Bray, G. A. The effect of intrahypothalamic injections of glucose on sympathetic efferent firing rate. Brain Res. Bull. 18, 591-595 (1987).

41. Sakaguchi, T. \& Bray, G. A. Intrahypothalamic injection of insulin decreases firing rate of sympathetic nerves. Proc. Natl Acad. Sci. USA 84, 2012-2014 (1987).

42. Sakaguchi, T., Arase, K. \& Bray, G. A. Sympathetic activity and food intake of rats with ventromedial hypothalamic lesions. Int J. Obes. 12, 285-291 (1988).

43. Vissing, J., Wallace, J. L., Scheurink, A. J., Galbo, H. \& Steffens, A. B. Ventromedial hypothalamic regulation of hormonal and metabolic responses to exercise Am. J. Physiol. 256, R1019-R1026 (1989). 
44. Sakaguchi, T. \& Bray, G. A. Ventromedial hypothalamic lesions attenuate responses of sympathetic nerves to carotid arterial infusions of glucose and insulin. Int J. Obes. 14, 127-133 (1990).

45. Shimazu, T., Sudo, M., Minokoshi, Y. \& Takahashi, A. Role of the hypothalamus in insulin-independent glucose uptake in peripheral tissues. Brain Res. Bull. 27, 501-504 (1991).

46. Sudo, M., Minokoshi, Y. \& Shimazu, T. Ventromedial hypothalamic stimulation enhances peripheral glucose uptake in anesthetized rats. Am. J. Physiol. 261 E298-E303 (1991).

47. Musatov, S. et al. Silencing of estrogen receptor alpha in the ventromedial nucleus of hypothalamus leads to metabolic syndrome. Proc. Natl Acad. Sci. USA 104, 2501-2506 (2007).

48. Klockener, T. et al. High-fat feeding promotes obesity via insulin receptor/PI3Kdependent inhibition of SF-1 VMH neurons. Nat. Neurosci. 14, 911-918 (2011).

49. Lin, D. et al. Functional identification of an aggression locus in the mouse hypothalamus. Nature 470, 221-226 (2011).

50. Kim, K. W. et al. FOXO1 in the ventromedial hypothalamus regulates energy balance. J. Clin. Invest. 122, 2578-2589 (2012).

51. Mobbs, C. V., Moreno, C. L. \& Poplawski, M. Metabolic mystery: aging, obesity, diabetes, and the ventromedial hypothalamus. Trends Endocrinol. Metab. 24 488-494 (2013).

52. Toda, C. et al. Extracellular signal-regulated kinase in the ventromedial hypothalamus mediates leptin-induced glucose uptake in red-type skeletal muscle. Diabetes 62, 2295-2307 (2013).

53. Correa, S. M. et al. An estrogen-responsive module in the ventromedial hypothalamus selectively drives sex-specific activity in females. Cell Rep. 10 62-74 (2015).

54. Wang, L., Chen, I. Z. \& Lin, D. Collateral pathways from the ventromedial hypothalamus mediate defensive behaviors. Neuron 85, 1344-1358 (2015).
55. Fujikawa, T. et al. SF-1 expression in the hypothalamus is required for beneficial metabolic effects of exercise. Elife 5, pii: e18206 (2016).

56. Meek, T. H. et al. Functional identification of a neurocircuit regulating blood glucose. Proc. Natl Acad. Sci. USA 113, 14 (2016).

57. Stanley, S. A. et al. Bidirectional electromagnetic control of the hypothalamus regulates feeding and metabolism. Nature 531, 647-650 (2016).

58. Knehans, A. W. \& Romsos, D. R. Norepinephrine turnover in obese (ob/ob) mice: effects of age, fasting, and acute cold. Am. J. Physiol. 244, E567-E574 (1983).

59. Seydoux, J., Rohner-Jeanrenaud, F., Assimacopoulos-Jeannet, F., Jeanrenaud, B. \& Girardier, L. Functional disconnection of brown adipose tissue in hypothalamic obesity in rats. Pflug. Arch. 390, 1-4 (1981).

60. Saito, M. \& Shimazu, T. Decreased rate of fatty acid synthesis in brown adipose tissue of hypothalamic obese rats. FEBS Lett. 166, 151-154 (1984).

61. Seydoux, J. et al. Decreased guanine nucleotide binding and reduced equivalent production by brown adipose tissue in hypothalamic obesity. Recovery after cold acclimation. FEBS Lett. 146, 161-164 (1982).

62. Choi, Y. H., Fujikawa, T., Lee, J., Reuter, A. \& Kim, K. W. Revisiting the ventral medial nucleus of the hypothalamus: the roles of SF-1 neurons in energy homeostasis. Front. Neurosci. 7, 71 (2013).

63. Cheung, C. C., Kurrasch, D. M., Liang, J. K. \& Ingraham, H. A. Genetic labeling of SF-1 neurons in mice reveals $\mathrm{VMH}$ circuitry beginning at neurogenesis and development of a separate non-SF-1 neuronal cluster in the ventrolateral VMH. J. Comp. Neurol. 521, 1268-1288 (2012).

64. Sternson, S. M., Atasoy, D., Betley, J. N., Henry, F. E. \& Xu, S. An emerging technology framework for the neurobiology of appetite. Cell Metab. 23 234-253 (2016) 